\title{
Os múltiplos sentidos da palavra direito em meio a fenômenos normativos plurais
}

\author{
Multiple renderings of the word law amid plural \\ normative phenomena
}

\author{
Hugo Luís Pena Ferreira \\ Universidade Federal de Goiás
}

Resumo O presente ensaio propõe apontar, em caráter introdutório, os múltiplos sentidos assumidos pelo termo "direito". A abordagem é feita a partir de dois grandes recortes, que buscam caracterizar sentidos do direito institucionalizado como norma, de um lado, e do direito como representação intelectual, de outro. Nesses recortes, questões como papéis do direito, fontes de normatividade jurídica, aplicação e processos dinâmicos emergem e são problematizadas. Da multiplicidade semântica do "direito", o texto parte para a pluralidade de fenômenos normativos com implicações para a estruturação de padrões de interação e ação de pessoas e governos. O ensaio tem o objetivo de servir de introdução tanto à pluralidade de sentidos para o direito quanto ao olhar pluralista $\mathrm{a}$ respeito da normatividade na sociedade. Aponta-se, assim, que embora seja um dos discursos disponíveis para fazer referência à normatividade na sociedade, o direito não tem o monopólio das emanações normativas relevantes. Nesse sentido, a porção final do texto destaca a perda do espaço do direito - sobretudo para a economia - como quadro de referência para o exercício da autoridade, atribuída à prevalência de uma perspectiva jurídica convencional de caráter dogmático, formalista, e fechada a elementos de outras esferas de saber e prática.

Palavras-chave: Direito. Semântica. Pluralismo. 
Abstract The present essay undertakes to understand the multiple meanings of said word through two broader analytical groupings (law institutionalized as norm; law as intellectual representation). In these groupings, issues such as the roles played by law, sources of legal normativity, legal applicability and dynamic legal processes are approached. From the multiple meanings of "law", the paper heads to the plurality of normative phenomena which take part in structuring action and interaction patterns of people and governments. The essay aims at providing an introduction both to the semantic plurality of law and to a pluralist approach to normative occurrences in society. It highlights, therefore, that although law is one of the discourses available to make pronouncements regarding normativity in society, it does not hold a monopoly on relevant normative emanations. Hence, the final part of the paper rather draws attention to the loss of space undergone by law (especially vis-a-vis economics) as a frame of reference for the exercise of authority, which may be attributed to the prevalence of a conventional legal perspective characterized by an approach that is dogmatic, formalist and inflexible to elements from other areas of knowledge and practice.

Key-words: Law. Semantics. Pluralism.

\section{INTRODUÇÃO}

O presente artigo pretende servir como introdução aos significados mais importantes assumidos pela expressão "direito" como uma - mas certamente não a única - referência a fenômenos de normatividade. $\mathrm{O}$ texto pretende ser útil sobretudo a quem inicia os estudos na área jurídica, e normalmente se depara com múltiplas acepções que o termo assume. As diferenças de sentido nem sempre são, porém, apontadas com clareza. Diante disso, o objetivo é introduzir a riqueza semântica do direito e as distintas implicações do modo como o termo é utilizado, sem fechar os olhos para outras emanações normativas que coexistem com o direito.

Para cumprir esse propósito, o texto encontra-se estruturado da seguinte maneira: A primeira seção estabelece um sentido geral para o "direito". Busca, além disso, diferenciá-lo de outros fenômenos normativos que também incidem sobre a ordenação das relações sociais. A 
seção ainda aponta - de maneira não exaustiva - diferentes papéis que o direito exerce na sociedade.

A segunda seção, por sua vez, registra as principais acepções da palavra "direito" e propõe navegar por elas a partir dos recortes de "direito institucionalizado como norma" - abrangendo suas fontes, aplicação e processos de transformação - e "representações jurídicas".

Por último, a terceira seção enfatiza o direito como um dos discursos disponíveis para dar conta de ocorrências normativas na sociedade, mas sem exclusividade. Retira, a partir disso, a necessidade de abertura do direito para a compreensão de fenômenos relevantes, que convencionalmente, não são capturados por suas lentes. Sugere, ainda, que o fechamento jurídico a elementos de outras esferas de saber e prática guarda relação com a perda de espaço que o direito experimentou, sobretudo ao longo do último século, para referenciais que, com maior êxito, proveram materiais para a estruturação de padrões de interação e ação de pessoas e governos (notadamente, saberes econômicos).

\section{DiReito: BREVES APONTAMENTOS A RESPEITO DE SEUS CONTOR- NOS E ALGUNS DE SEUS PAPÉIS}

O direito é um dos referenciais de que fazem uso as autoridades do Estado para ordenar relações sociais (CASTRO, 2012, p. 22). No fundo, o direito está envolvido com a "legitimação consensual do poder" (2012, p. 30), sendo uma das respostas apresentadas ao "problema do poder", ou seja, à presença da violência nas interações sociais e em especial no exercício da autoridade. $\mathrm{O}$ direito, nesse sentido, fornece materiais para a estruturação de relações políticas, econômicas e sociais. Mas não o faz sozinho, nem o fez sempre.

A filosofia política grega precedeu o direito como fonte de elaborações a respeito do problema do poder. ${ }^{1}$ Mas formulações propriamen-

1 Tanto a filosofia política como o direito foram respostas à estruturação das relações sociais fundadas na tradição, no costume e em formas religiosas, que justificavam interações sociais fundadas na violência. Em outros termos, ambos são respostas ao que Castro (2012) identifica como "problema do poder". 
te "jurídicas"2 só emergiram com a jurisprudentia romana, que "auxiliou os romanos a modificar paulatinamente o seu costume tradicional", a modificar "aos poucos sua maneira de perceber o mundo" e "o modo de estruturar diversas de suas relações sociais" (CASTRO, 2012, p. 38). É importante perceber que a jurisprudentia romana representou a possibilidade de liberdade em relação à realidade determinada pelos costumes impostos pelas tradições. Caracterizava, assim, um meio para operar transformações, contestar a ordem herdada, e modificar relações sociais (2012, p. 42). ${ }^{3}$ Com a jurisprudentia romana, tomava contornos um formato propriamente jurídico (isto é, autônomo em relação à filosofia) de referenciais para lidar com o problema do poder e as relações na sociedade (cf. CASTRO, 2012).

Como já se salientou, o direito estrutura relações sociais. Define, molda padrões de ação i) de pessoas e governos, ii) de pessoas entre si, iii) de governantes e governados e iv) de governos uns com os outros (caso da normatividade jurídica no plano internacional). É possível refinar essas afirmações, abordando-as por outro enfoque: o direito envolve a escolha dos interesses a proteger entre aqueles correntes na sociedade, como afirma David Kennedy (2011). ${ }^{4}$

Os interesses consolidam-se em titularidades quando são abrigados pelo direito, e as titularidades são posições juridicamente protegidas, que

2 Para Marcus Faro de Castro, "apenas os processos institucionais e intelectuais que possam, em aspectos relevantes, ser comparados com a jurisprudentia dos romanos (...) deveriam merecer a designação de "direito"” (2012, p. 220).

3 Marcus Faro de Castro salienta que a jurisprudentia romana não estava presa às formas (nem jurídicas, nem filosóficas). Isso não quer dizer que formas jurídicas não eram produzidas ou empregadas. No entanto, a operação desse direito não estava presa nem às formas jurídicas, nem àquelas oriundas da filosofia. Nesse sentido, a jurisprudentia configurou “um certo 'formalismo pragmático' como estilo de desenvolvimento de referenciais normativos" (2012, p. 41). O formalismo pragmático, também característico dos sistemas de common law até hoje, permite que as formas jurídicas sejam "adaptadas, ou variantes (...) criadas, para dar conta de novas maneiras de perceber os fatos e impulsionar mudanças na ordem da sociedade" (2012, p. 57).

4 O artigo de David Kennedy (2011) tem como tema central a contestação da tese do neoinstitucionalismo econômico de que a definição forte e clara de direitos de propriedade conduziria (ou, ao menos, seria necessária) ao desenvolvimento. $\mathrm{O}$ foco é, portanto, em direitos de propriedade, mas o raciocínio ancorado em titularidades como consolidações jurídicas de interesses pode ser estendido para raciocinar sobre outras relações jurídicas. 
se traduzem na ideia mais formal de direitos subjetivos. Para David Kennedy, o tensionamento entre interesses distintos reflete-se na implementação e evolução das titularidades com o passar do tempo (2011, p. 13). Ainda, segundo o autor, "atores econômicos de peso em toda economia tentam usar suas titularidades para consolidar suas posições políticas e econômicas" (2011, p. 12). Em contrapartida, interesses de grupos e indivíduos emergentes tenderão a contestar titularidades existentes, para consolidar sua própria (nova) posição na ordem jurídica, reformando-a.

Certo ponto ressaltado por Kennedy, quanto a esta formulação, é bastante relevante: estratégias de desenvolvimento requerem escolhas "de profunda significância" entre os vários interesses econômicos existentes e entre modos de definição de titularidades (2011, p. 3-5). Que as posições juridicamente protegidas sejam produto de escolhas, e não de dotações de origem metafísica, é importante para afastar discursos a respeito da neutralidade ou da naturalidade das instituições jurídicas.

A partir destas breves considerações, feitas com base em Castro (2012) e Kennedy (2011), interpreta-se que o direito pode assumir diferentes papéis. Três deles, de caráter bastante geral, serão aqui destacados.

Primeiramente, o direito pode consolidar titularidades em formas jurídicas, de modo a resistir a interesses emergentes (caso em que exerce papel conservador). Nessa configuração, o(a) jurista privilegia a aplicação de formas existentes à sua adaptação, e o conceitualismo prepondera. Busca-se a preservação das hierarquias existentes na sociedade.

Em segundo lugar, o direito pode abrigar novos interesses preponderantes, transformando ou adaptando as formas jurídicas para conciliar a estruturação das titularidades com a realidade social transformada (nesse caso, o direito é uma ferramenta de legitimação de transformações já ocorridas). Nessa configuração, "joga-se" pragmaticamente com as formas, de modo a manter a coesão entre as "formas jurídicas" e a "matéria" do social. Busca-se que o direito reconheça as novas relações hierárquicas existentes na sociedade. ${ }^{5}$

Em terceiro lugar, o direito pode remanejar titularidades, de modo

Esse seria o "formalismo pragmático" mencionado por Castro (2012), e que caracterizaria tanto a jurisprudentia romana quanto a operação do direito nos sistemas de common law. 
a afetar interesses existentes e, com isso, modificar ou dar origem a novos padrões de relações sociais e econômicas (nesse caso, o direito é uma ferramenta de transformação social e econômica). Nessa configuração, a realidade é rearticulada juridicamente, de modo a permitir, por exemplo, a "habilitação econômica de indivíduos e grupos", ${ }^{6}$ objetivando estruturar interações sociais mais equânimes. Busca-se subverter hierarquias existentes na sociedade.

Depreende-se que o direito tem pluralidade de papéis quanto à ordenação das relações políticas, econômicas e sociais, podendo ser ferramenta para conservar hierarquias tradicionais diante de uma realidade em transformação, abraçar novas hierarquias por meio de reformas, ou subverter hierarquias em busca da promoção da liberdade de indivíduos e grupos.

Outro autor que destaca a multiplicidade de papéis ou funções para o direito é Diogo Coutinho (2013). Para o autor, o direito "não apenas define e cristaliza, a seu modo, fins substantivos, como ainda molda e forja instituições encarregadas de persegui-los, influenciando, ainda, as ações e processos destinados a implementar políticas públicas" (COUTINHO, 2013, p. 96). Essa caracterização engloba quatro papéis correspondentes a quatro dimensões jurídicas.

O direito pode ser encarado "como objetivo" ao "formalizar metas e indicar os "pontos de chegada" das políticas públicas (2013, p. 99). Essa função corresponde à dimensão substantiva (2013, p. 102), de definição de conteúdos desejados para ação governamental, a exemplo do que ocorre com normas programáticas ${ }^{7}$ presentes na Constituição de 1988 (cf. COUTINHO, 2013, p. 99).

6 "[A]s autoridades públicas podem promover a explícita habilitação econômica de indivíduos e grupos, incluindo-os nos circuitos de produção, troca e consumo da economia de mercado; ou, ao contrário, podem provocar a marginalização ou inabilitação econômica (relativa ou até absoluta) de indivíduos e grupos" (CASTRO, 2010, p. 19).

7 Por exemplo, tem caráter programático a norma constitucional (Art. $7^{\circ}$. IV) segundo a qual o salário mínimo deve ser "capaz de atender a suas necessidades vitais básicas e às de sua família com moradia, alimentação, educação, saúde, lazer, vestuário, higiene, transporte e previdência social, com reajustes periódicos que lhe preservem o poder aquisitivo (...)." 
O direito também exerce papel de "ferramenta", porque a "seleção e a formatação dos meios a serem empregados para perseguir os objetivos predefinidos são um trabalho jurídico" (COUTINHO, 2013, p. 99). Essa dimensão instrumental (2013, p. 102) envolve "a escolha dos instrumentos de direito administrativo mais adequados", o "desenho de mecanismos de indução ou recompensa", bem como, de sanções, para estimular ou desencorajar comportamentos, e a "seleção do tipo de norma a ser utilizada" na implementação de uma política pública. ${ }^{8}$

Em sua terceira função, o direito atua como "arranjo institucional", partilhando "responsabilidades entre atores públicos e privados" na condução de uma política e definindo "estruturas jurídicas capazes de fazer que os objetivos se convertam em ações ancoradas na escolha de ferramentas, de modo que não haja, do ponto de vista da divisão de tarefas, sobreposições, lacunas ou rivalidades em políticas públicas" (COUTINHO, 2013, p. 100). Essa é a dimensão estruturante do direito, segundo Coutinho (2013, p. 102). ${ }^{9}$

Por fim, o direito exerce a função de "vocalizador de demandas", podendo "prover (ou desprover) as políticas de mecanismos de deliberação, participação, consulta, colaboração e decisão conjunta" (COUTINHO, 2013, p. 101). ${ }^{10}$ Essa dimensão legitimadora do direito se relaciona com a criação de mecanismos propícios ao "experimentalismo democrático" na definição das políticas públicas e da política econômica. Nesse sentido, Coutinho reforça que:

8 A fixação da pena de reclusão para quem comete homicídio (Art. 121 do Código Penal) é um exemplo de sanção inibidora de comportamentos, a caracterizar o direito em sua dimensão instrumental, ou o direito como ferramenta.

9 Exemplos de direito como arranjo estrutural podem ser visualizados nas Parcerias Público-Privadas (PPPs) - a exemplo das concessões de aeroportos, rodovias, saneamento e iluminação pública -, que definem papéis para empresas e entidades governamentais em ações conjuntas, ligadas a obras e serviços públicos.

10 A exemplo de audiências públicas, da famosa experiência com Orçamento Participativo em Porto Alegre, além de mecanismos mais tradicionais, como a iniciativa popular de projeto de lei, o plebiscito e o referendo. 


\begin{abstract}
...normas jurídicas podem levar políticas públicas a serem mais democráticas uma vez que, por meio de regras procedimentais que disciplinem consultas e audiências públicas e a publicidade dos atos administrativos, as obriguem a estar abertas aos inputs de uma pluralidade de atores (COUTINHO, 2013, p. 101).
\end{abstract}

Nota-se, portanto, que afirmar que o direito estrutura relações sociais, definindo padrões de ação e interação de pessoas e governos, não é o suficiente para capturar a grande diversidade de papéis ou funções que o direito pode exercer. Como visto, o direito consolida interesses em posições juridicamente protegidas, que correspondem a titularidades. Mas isso não diz tudo, já que a formalização jurídica das titularidades pode assumir sentidos variados: o direito pode ser usado i) para conservá-las frente a uma realidade em transformação; ii) para abrigar novos interesses preponderantes, legitimando-os; e iii) remanejar titularidades, promovendo transformação social. Por fim, como observado, também é possível conceber que o direito seja empregado como: i) objetivo; ii) ferramenta; iii) arranjo institucional e iv) vocalizador de demandas.

\title{
DOIS GRANDES RECORTES PARA ACEPÇÕES DA PALAVRA "DIREITO"
}

Além de papéis plurais, o direito, ou melhor, o termo "direito", dá margem a uma pluralidade de acepções. Afinal, há direito subjetivo e objetivo, direito como campo do conhecimento, objeto de estudo e profissão, direito como instituições jurídicas, direito como produção normativa e práticas judiciais, e direito como aspirações não oficialmente reconhecidas, mas que compõem o linguajar dos embates sociais, políticos e econômicos.

Para navegar por essa pluralidade de possibilidades de sentido, será útil adotar um procedimento ancorado em distinção feita por Castro (2012, p. 19), que consiste no "direito institucionalizado como norma", de um lado, e nas representações intelectuais acerca das normas nas rela- 
ções sociais, de outro. Desse modo, é possível estruturar a compreensão a partir de dois grandes grupos de sentidos para o direito, que por sua vez permitem abrigar diversos componentes de maneira mais organizada.

\section{Direito inSTITUCIONALIZADO COMO NORMA: FONTES,} APLICAÇÃO E DINÂMICA

O direito institucionalizado como norma evoca, de plano, a referência ao direito objetivo. Este remete às instituições jurídicas reconhecidas no ordenamento, quer na constituição, em leis, decretos, portarias ou na jurisprudência, aqui entendida como precedentes judiciais concatenados que afirmam uma norma jurídica. Em termos mais simplificados, o direito objetivo pode ser entendido como a previsão normativa, em abstrato. Na perspectiva jurídica tradicional, os direitos subjetivos derivam das previsões do direito objetivo. Hans Kelsen, por exemplo, concebe o direito subjetivo como a individualização de preceitos objetivos. Para ele, falar em direito subjetivo é considerar "o direito apenas do ponto de vista dos interesses das partes, levando em conta o seu significado para o indivíduo, enquanto lhe é útil” (2011, p. 119).

As instituições jurídicas transitam entre seu significado abstrato de "direito objetivo" e sua concretização em "direitos subjetivos". Por exemplo, a instituição da imunidade tributária para livros no ordenamento jurídico brasileiro, ${ }^{11}$ como previsão abstrata, é direito objetivo. A partir do momento que uma pessoa concretamente importa um livro, tal instituição se torna para essa pessoa um direito subjetivo que, no caso, significa o direito de não pagar tarifas de importação sobre aquele livro.

Outra maneira de compreender esses contornos é pensar que as instituições jurídicas representam duas faces, uma genérica e abstrata, outra individualizada e concreta; a primeira referindo-se ao direito objetivo, e a segunda, ao direito subjetivo. Assim, quando uma pessoa se encontra em uma posição juridicamente protegida, ela invoca o direito subjetivo a partir da previsão normativa da ordem jurídica, ou direito objetivo. Ao

11 Artigo 150, VI, “d” da Constituição da República Federativa do Brasil, de 1988. 
menos essa é a perspectiva jurídica tradicional, para a qual os direitos subjetivos já encontram seus conteúdos "prontos" a partir do direito objetivo. Essa, porém, não precisa ser a única forma de representá-los.

Antes de abordar o outro lado da moeda, ou seja, o direito como representação intelectual, campo ou saber, é importante ressaltar aspectos relacionados às fontes, à aplicação e à dinâmica do direito institucionalizado como norma. $\mathrm{O}$ direito institucionalizado como norma não vem do nada. Há fontes de normatividade. A pergunta relevante se torna: o que produz direito?

As respostas são múltiplas. ${ }^{12}$ As atividades dos poderes do Estado produzem normas. O legislativo é o caso mais claro, mas esse poder não tem o monopólio da produção normativa. A atividade do poder executivo é geradora de normas, bem como, a do poder judiciário. Ainda no campo das atividades estatais, porém com uma visão para o externo, a cooperação internacional também gera normas. Tratados, decisões de cortes internacionais, resoluções e decisões de organizações internacionais, entre outros: todos estes têm significado normativo, ainda que em muitos casos se aplique uma distinção entre hard e soft law, ${ }^{13}$ e que nem sempre se possa encontrar meios coercitivos de sancionar o descumprimento da norma que sejam análogos aos disponíveis no direito doméstico.

12 Adota-se, aqui, uma visão pluralista a respeito da normatividade jurídica, que remete à perspectiva do pluralismo jurídico global e do direito e globalização, apresentados em Berman (2005) e Berman (2007).

13 Hard law é o direito cuja força vinculante (binding character) é reconhecida. Soft law são normas de caráter propositivo, incipiente, e cuja adesão flui de necessidades técnicas, práticas ou políticas, mas que não têm suficiente obrigatoriedade em sentido jurídico convencional. As normas de soft law não possuem caráter vinculatório, mas meramente programático. A soft law introduz elementos de relatividade normativa nas relações jurídicas, dando a entender que certas normas estão em estágio mais finalizado do que outras. Em artigo paradigmático, Prosper Weil (1983) levantou (e atacou) a ideia de relatividade normativa no direito internacional público: as normas vistas ao longo de uma escala de intensidade normativa, umas normas mais "normas" que outras. No Brasil, o principal estudo sobre o tema foi conduzido por Salem Hikmat Nasser (2006). 
Nem só o Estado produz direito. ${ }^{14} \mathrm{~A}$ atividade privada também provê conteúdos com significado normativo, por meio de contratos formais e informais. E as práticas sociais podem gerar instituições com significado jurídico, que se enquadram no gênero dos "costumes", entendidos como práticas reiteradas a que se atribui sentido de obrigatoriedade.

Mesmo no plano internacional ou transnacional, a atividade privada e social, isto é, não estatal, é capaz de gerar normatividade. Exemplos concretos são abundantes na era da globalização. Assim, o padrão "ISO 9000" emana de uma organização não governamental, mas empresas nos mais variados cantos do globo condicionam na prática seus comportamentos de gestão com base nele. No campo monetário, a BitCoin é uma criptomoeda cujas regras estão incrustadas em algoritmos que permitem a operação automática de uma rede global peer-to-peer (usuário a usuário), sem centro, e que escapa aos controles governamentais. Há padrões bancários e contábeis de abrangência global e que emanam de entidades que não se situam no âmbito da cooperação governamental (cf. HALL; BIERSTEKER, 2004).

Outro aspecto importante do direito institucionalizado como norma é o de sua aplicação. As instituições jurídicas podem se concretizar de maneira espontânea, no sentido de que as pessoas, sem constrangimentos iníquos, moldam seu comportamento por noções jurídicas do que é devido fazer. A aplicação da norma jurídica, porém, pode contar com aparatos coercitivos ou com outras formas de constrangimento que não chegam a caracterizar a coerção (ver mais adiante).

O processo judicial é a resposta tradicional do(a) jurista para o conflito envolvendo a interpretação do sentido e a aplicação forçada das normas jurídicas. Nele, em última análise, busca-se o Estado para assegurar o respeito, pela coerção, a uma posição juridicamente protegida, a uma titularidade. Essa coerção, embora possa alcançar o uso da violência física, é considerada legítima por padrão. Nesse sentido, o

14 A crítica ao fechamento do olhar jurídico a fenômenos normativos derivados da atividade estatal é feita pelos proponentes do pluralismo jurídico. Ver Wolkmer, 2001. No âmbito da normatividade internacional, existe a vertente do "pluralismo jurídico global" (cf. BERMAN, 2005; 2007). 
direito opera poderes "mágicos" de transformação da violência em algo "normal" e aceitável (MANSELL; METEYARD; THOMSON, 2004, p. 5, 75) para conseguir a obediência.

Mas não se deve ter uma noção restrita a respeito da aplicação do direito. Não se trata apenas de espontaneidade ou processo judicial. Há processos de tipo judicial que não são domésticos e não contam com ferramentas propriamente coercitivas, como aqueles que se desenrolam no âmbito de tribunais internacionais, que julgam demandas contra Estados. Há processos que não são judiciais, mas que igualmente cuidam da aplicação do direito, como procedimentos arbitrais. Há meios de solução de controvérsias jurídicas que podem se dar fora do contexto judicial ou arbitral, como a conciliação, a mediação e as comissões de inquérito (fact finding). E há articulações para a aplicação de prescrições de "dever ser" que fogem ao sentido tradicional do que o(a) jurista entende como "sanção", mas que são capazes de, na prática, constranger comportamentos de pessoas, empresas, Estados e outras entidades, ainda que emanem de autoridades privadas (HALL; BIERSTEKER, 2004; LAKE, 2010).

Por exemplo, as agências de classificação do risco da dívida soberana, isto é, dos títulos da dívida pública emitidos pelos Estados, como a Moody's, a Fitch Ratings e a Standard \& Poor's, são entidades privadas que emitem pareceres a respeito da segurança dos investimentos, e que balizam, na prática, o comportamento de uma multidão difusa de investidores internacionais (LAKE, 2010). Nesse contexto, o rebaixamento da nota dos títulos da dívida pública de um país funciona como algo análogo a uma "sanção" à adoção de políticas públicas ou de medidas de política econômica encaradas pela comunidade dos investidores internacionais como atentatórios à rentabilidade ou à segurança do capital confiado ao Estado.

Transparece o sentido de "dever ser" reforçado por esse constrangimento que, embora simbólico (é uma nota, afinal), tem repercussões econômicas muito fortes: o Estado deve assegurar que o investimento seja rentável e seguro. Na prática, o poderoso argumento da "fuga de capital" funciona como veto privado à adoção de medidas governamen- 
tais que contrariem esse sentido da normatividade empírica das finanças internacionais (HELLEINER, 1994, p. 173).

\begin{abstract}
Se uma só nação, mesmo com governo popularmente eleito, muda para políticas radicais, o capital financeiro pode evadir-se; mesmo a burguesia ("capital humano") pode emigrar, votando com seus pés. Ao mesmo tempo, novas fontes estrangeiras de financiamento podem secar, exacerbando a crise. Governos, contemplando tal resultado, podem rejeitar guinadas políticas à esquerda, ou mesmo ao tentá-las, podem ser forçados a retraçar seus rumos em meio ao caos (BHAGWATI, 2004, p. 97).
\end{abstract}

Parece certo, porém, que as representações jurídicas tradicionais falhem em capturar esse tipo de constrangimento (CASTRO, 2006; 2012), que se mostrou especialmente relevante nos anos de 2015 e 2016 no Brasil.

Outro ponto importante: as instituições jurídicas não são estáticas. $\mathrm{O}$ que as pessoas identificam como o direito objetivo, ou invocam para si como direito subjetivo, está sujeito a alterações com o passar do tempo. $\mathrm{O}$ direito institucionalizado como norma tem engastes com a dinâmica social, política, econômica e cultural (CASTRO, 2006; 2012). Afinal, é "um fenômeno contingente e socialmente construído, que não tem existência ou papel natural, mas que tem uma função relacionada à estrutura econômica, à divisão da riqueza na sociedade e à ideologia daqueles com poder na sociedade" (MANSELL; METEYARD; THOMSON, 2004, p. vi).

A perspectiva jurídica tradicional incorpora o aspecto da mudança nas instituições jurídicas por meio da doutrina das fontes, e não por referências à estrutura econômica, à distribuição de riquezas ou ao exercício do poder político na sociedade. Ou seja: concebe-se que direito institucionalizado como norma possa mudar pela atividade legislativa (quer ocorra no poder legislativo, quer no executivo, por meio de medidas provisórias, decretos de regulamentação e atos administrativos), pela reorientação jurisprudencial e por práticas sociais 
que geram novos costumes e colocam normas antigas em desuso. Mas não muito mais do que isso.

Juristas internacionalistas acrescentariam a esse rol os tratados internacionais e as decisões vinculantes de organizações internacionais, como certas resoluções do Conselho de Segurança da Organização das Nações Unidas (ONU) ou os resultados de painéis da Organização Mundial do Comércio (OMC). Parte desses juristas, porém, faria exigências de que essas medidas normativas internacionais fossem incorporadas ao ordenamento jurídico doméstico antes que pudessem surtir efeitos jurídicos "válidos".

O problema nesse uso tradicional da doutrina das fontes, com ou sem a incorporação dos efeitos da normatividade internacional no plano doméstico, consiste em seu caráter limitado para explicar mudanças nas instituições jurídicas. No fundo, tal doutrina se ocupa unicamente das fontes "formais" de normatividade. Ao fazê-lo, deixa de fora importantes e múltiplas emanações práticas de normatividade cujo caráter é informal.

Para compreender com lentes mais amplas a dinâmica do direito institucionalizado como norma, é necessário lançar mão da interdisciplinaridade (CASTRO, 2012). Só assim se pode passar a capturar emanações de normatividade com relevância prática, mas que não são tradicionalmente abarcadas pelas formas jurídicas existentes.

Por exemplo, a ciência política pode fornecer insumos interessantes para explicar tanto a persistência de certas instituições jurídicas quanto rupturas e alterações em ritmo mais ou menos acelerado de outras. Certos autores buscam explicar processos de ruptura, permanência ou mudança incremental por categorias como conjunturas críticas, dependência da trajetória (path dependence), processos de retroalimentação (positive feedbacks) e legados históricos (PIERSON, 2004; COLLIER, R.; COLLIER, D., 2002). Outros desenvolvem instrumentais para explicar mudanças graduais por meio de processos variados, como deslocamentos, desvios (drifts), sobreposição e conversão institucional (STREECK; THELEN, 2005; MAHONEY; THELEN, 2010). $\mathrm{O}$ (a) jurista também se beneficiaria desse tipo de instrumental para compreender a dinâmica do direito institucionalizado como norma. 
Outro passo para além da formalidade na abordagem da doutrina das fontes é dado, no âmbito de uma literatura jurídica interdisciplinar, pela vertente de "ordenação jurídica transnacional" (transnational legal ordering), de Gregory Shaffer (2013). ${ }^{15}$ Embora não seja o objetivo deste texto caracterizá-la, cabe pontuar que ela permite compreender engastes entre o que se considera o direito local e processos transfronteiriços de criação, migração, e interação de normas jurídicas, e que não são capturados pelo discurso jurídico tradicional.

Todas essas considerações são importantes, porque a compreensão de processos dinâmicos do direito institucionalizado como norma precisa acontecer para que o(a) jurista seja capaz de apreender, acompanhar, e atuar sobre uma realidade que é essencialmente dinâmica, com fluxos intensos e de longa distância de pessoas, bens, informações, e também de normas. O olhar jurídico de uma época em que certos fenômenos têm escala global, e feições transnacionais, precisa ter abertura a processos institucionais que não podem ser compreendidos à luz de perspectivas jurídicas convencionais, de caráter formalista e fechadas a elementos interdisciplinares. ${ }^{16}$

Nesse sentido, e dialogando ainda com as contribuições de Paul Schiff Berman (2005; 2007), é importante compreender o direito como parte constitutiva da cultura, que determina e molda relações sociais. $\mathrm{O}$ direito institucionalizado como norma não está preso somente às atividades oficiais estatais, nem às formas jurídicas tradicionais, mas reflete também a maneira como as pessoas concebem e definem o modo "normal" ou "natural" de se fazer as coisas, os padrões habituais de ação e de fala, e a percepção de mundo, incluindo aspectos do que é correto e devido. Essa concepção dispensa, embora não despreze, a definição de

\footnotetext{
15 A perspectiva da ordenação jurídica transnacional enfatiza interpenetrações entre direito local e processos jurídicos transnacionais. Nesse sentido, sua principal afirmação é a de que "em vastas áreas do direito hoje, não é possível compreender a prática e a mudança jurídica doméstica sem compreender a ordenação jurídica transnacional" (SHAFFER, 2013, p. 2). Ou seja, há engastes entre o que se considera direito local e processos transfronteiriços de migração de normas jurídicas.

16 Essa preocupação é um dos pontos centrais na obra "Formas jurídicas e mudança social" (CASTRO, 2012).
} 
direito que se limita a enxergar normatividade "jurídica" em emanações do Estado que contem com a possibilidade de imposição coercitiva. $\mathrm{O}$ “jurídico", mais amplamente do que isso, está atrelado a expressões de normatividade no dia a dia das pessoas, das empresas, dos Estados e de outras organizações. Expressões de normatividade que, oficiais ou não, coercitivas ou não, influenciam seus comportamentos na prática (BERMAN, 2005, p. 493-497; cf. WOLKMER, 2001).

\section{DiREITO COMO REPRESENTAÇÃo JURÍDICA E SUA RELAÇÃo DI- NÂMICA COM INSTITUIÇÕES}

Embora as considerações mencionadas tenham se dirigido a processos de criação, aplicação e mudança do direito institucionalizado como norma, muitos de seus aspectos já adentram questões relativas às representações jurídicas. As representações jurídicas são discursos sobre as instituições jurídicas. Elas podem abranger tanto o formato passado quanto presente do direito institucionalizado como norma, como também podem articular transformações no direito. Ao passo que o Código Civil, a Constituição, a Carta das Nações Unidas e o costume do cheque pré-datado são exemplos de "direito institucionalizado como norma", o direito civil, constitucional e internacional público são alguns dos corpos de ideias que abrigam representações jurídicas a seu respeito. São campos, áreas do saber, disciplinas, ou até mesmo correntes de pensamento.

Mas a noção de representações jurídicas não se prende a campos ou disciplinas do conhecimento jurídico como entes monolíticos ou unitários. Cada campo admite divisões, embates, correntes teóricas divergentes, que são também formas mais específicas de representar o direito. No direito do trabalho, por exemplo, certo grupo de juristas interpreta relações trabalhistas à luz das categorias de direito privado, buscando promover sua "flexibilização". Outro grupo resiste a esses esforços enxergando a predominância de conteúdos de direito público, buscando reforçar o caráter indisponível de cláusulas protetivas do trabalhador. 
Disputas internas análogas a essa ocorrem nos mais diversos campos. E há divisões de nível macro, ou seja, de caráter muito abrangente, que se referem aos discursos a respeito da própria normatividade jurídica em geral. Por exemplo, jusnaturalismo, positivismo e neoconstitucionalismo ${ }^{17}$ têm respostas divergentes para o questionamento do que, afinal, confere direitos às pessoas, e desenvolvem discursos distintos a respeito da "validade" das normas jurídicas.

É importante compreender que as ideias e as instituições jurídicas se relacionam com influência recíproca. Por um lado, o formato do direito institucionalizado como norma afeta a percepção de juristas a seu respeito. Por outro lado, as representações intelectuais de juristas são capazes de moldar, transformar ou perenizar o direito institucionalizado, por atividades de crítica, emulação, reprodução pelo ensino e proposições doutrinárias de lege ferenda (ou seja, voltadas à inovação jurídica) e que podem influenciar o comportamento dos tribunais.

Essa relação dinâmica entre representações intelectuais, de um lado, e instituições, de outro, não é exclusividade do campo jurídico: também acontece no econômico, no político, no cultural etc. Marcus Faro de Castro chama a atenção para a existência de uma literatura que busca compreender o papel das ideias na formação, preservação e mudança das instituições, ou seja, que destaca "elementos ideacionais" (CASTRO, 2005, p. 170-1). Novamente, é útil lançar mão da interdisciplinaridade com a ciência política para mencionar algumas das categorias utilizadas pelos autores dessa literatura para representar a influência das ideias sobre as instituições.

Alguns desses autores, também referidos como "construtivistas", são Mark Blyth e Colin Hay. Blyth (2001) argumenta que as ideias podem funcionar como i) "plantas" para o desenho de instituições novas; como ii) "armas", caso em que são empregadas para contestar instituições existentes; e como iii) "cadeados cognitivos", hipótese em que operam de modo a reforçar as instituições mesmo diante de pressões por mudança, ou seja, desempenhando papel conservador. Hay (2006), por sua

17 Para uma comparação das três perspectivas aqui mencionadas, ver Pena, 2014. 
vez, aponta que os atores políticos apropriam-se estrategicamente de um mundo repleto de instituições e ideias sobre estas. Para Hay, a percepção a respeito do que é viável, legítimo, possível e desejável é tanto moldada pelo ambiente institucional quanto pelos paradigmas e visões de mundo existentes. Esses elementos operam como "filtros cognitivos" (2006, p. 65), que exercem influência sobre os padrões de ação das pessoas e dos governos. A importância das representações intelectuais (e especificamente jurídicas) para as políticas públicas (que são padrões de ação dos governos) é uma preocupação saliente em Castro (2012).

Para Castro, nesse sentido, os elementos ideacionais jurídicos têm papel a desempenhar na estruturação das relações sociais. Embora o direito possa exercer papel transformador, as representações jurídicas a respeito do direito, no Brasil, têm sido marcadas por formalismo e conceitualismo, do ensino jurídico à prática judicial (CASTRO, 2012). O impacto mais importante desse estilo de formação tradicional é a inabilitação do(a) jurista para avaliar políticas públicas (inclusive a política econômica e as políticas da cooperação econômica internacional) e propor reformas (consequentes) que as orientem a objetivos jurídicos.

Três resultados negativos da prevalência dessa visão [formal-conceitualista] sobre o direito no ensino jurídico brasileiro são: um descolamento entre o intelecto do jurista e a realidade social, que é muito mais complexa do que as categorias jurídicas são capazes de analisar; uma dificuldade para avaliar de maneira responsável e analiticamente apta as políticas públicas e seus impactos sobre a vida social, dando-lhes um significado jurídico útil; e também uma orientação intelectual para atuar apenas no sentido de preservar a ordem posta, não para reformá-la (CASTRO, 2012, p. 9).

Como consequência, no campo das políticas públicas, da política econômica e até mesmo da cooperação econômica internacional, o direito tende a assumir papel meramente instrumental. A coordenação de políticas passa a estar a cargo, sobretudo, de economistas. Até mesmo porque a 
...limitação que caracteriza boa parte dos debates jurídicos contemporâneos contrasta com a multiplicidade de instrumentos analíticos, procedimentos de cálculo e critérios operacionais desenvolvidos pelos economistas. Evidentemente, de maneira mais exitosa que os juristas, eles lograram elaborar 'formas' para a 'matéria' do social que se aplicam à sociedade vista como um 'sistema'. Certamente, o direito do Estado de bem-estar social, com suas 'formas' jurídicas viabilizadas pela 'turma do social' e, em seguida, de modo mais tortuoso, também pela análise jurídica das políticas públicas, até agora tem servido apenas como um complemento a políticas econômicas. E a coordenação mais abrangente das políticas públicas é realizada, para o bem ou para o mal, por meio do emprego de categorias macroeconômicas (CASTRO, 2012, p. 214).

Ou seja, as decisões fundamentais sobre conflitos distributivos são articuladas com saberes econômicos, não com os jurídicos. Esse estado de coisas é problemático por não favorecer a orientação de políticas ao atendimento de prioridades juridicamente estabelecidas, como direitos fundamentais. Nesse sentido, argumentos como "necessidade econômica" (sobretudo para evitar a "fuga de capital"), "eficiência" e "melhor relação custo/benefício" podem desbancar titularidades antes juridicamente consolidadas, servindo de impulso para alterações em normas constitucionais e legais, como recentes propostas de congelamento da despesa primária estatal por 20 anos, reforma previdenciária e trabalhista. Apesar de sua ainda inegável força no Brasil nos anos de 2015 e 2016, a credibilidade das orientações econômicas (oriundas de referenciais econômicos ortodoxos, ou neoclássicos) declinou mundialmente com a crise econômica na primeira metade do século XXI (CASTRO, 2012, p. 215), a chamada crise do subprime, iniciada em 2007 e aprofundada em 2008.

A coordenação das políticas pelo direito não é favorecida por perspectivas formalistas, porque as formas jurídicas tradicionais i) não geram representações intelectuais que permitam articular as necessidades de aumento da fruição de direitos com a competitividade econômica, ii) 
são elaborações estáticas, inadequadas para enfrentar realidades sociais dinâmicas e iii) têm pouca ou nenhuma sensibilidade a fenômenos normativos transnacionais, ou seja, não permite a visualização dos engastes entre o direito local e processos normativos transfronteiriços.

O direito precisa ser ressignificado. Não parece possível fazê-lo sem quebrar o fechamento tradicional do conhecimento jurídico, dedicado à abordagem formal e conceitual do direito institucionalizado como norma (e com foco nas emanações domésticas de direito positivo). As representações jurídicas precisam incorporar meios interdisciplinares de aproximação do mundo.

A seção seguinte busca abordar aspectos desse problema, ao propor que se encare o direito como um, mas não o único, discurso sobre a normatividade nas sociedades. Se até então a ênfase deste artigo esteve nas múltiplas acepções de funções e significados para o direito, aqui a ideia de multiplicidade é situada num plano mais amplo: passa-se a questionar a visão jurídica convencional segundo a qual apenas a normatividade de fundo "jurídico" importa.

\section{O DIREITO NÃO TEM O MONOPÓLIO DO DISCURSO SOBRE}

\section{A NORMATIVIDADE}

É comum identificar o direito como ferramenta de promoção da "ordem" na sociedade, e a ordem é, por sua vez, associada ao estado "normal" das coisas (MANSELL; METEYARD; THOMSON, 2004, p. 9). Como se observou na seção anterior, o direito, em suas representações tradicionais, tem um discurso limitado para compreender o "normal". Sua abordagem formalista, conceitual, representa uma perspectiva fechada em si mesma, e que busca capturar a normatividade por meio de articulações da doutrina das fontes, mas que não permite ao(à) jurista enxergar outras modalidades de estruturação do que é "normal", e que, portanto, contribuem para conformar ordens na sociedade (MANSELL; METEYARD; THOMSON, 2004).

Em outros termos, há mais fontes de estruturação do que é "normal", e do que integra a "ordem", do que as perspectivas tradicionais do 
direito são capazes de representar. Como o direito é um discurso sobre a normatividade na sociedade, ele precisa abrir-se para dar conta também das fontes que escapam às suas ferramentas tradicionais e formais de percepção. A tradição do(a) jurista de descartar elementos da realidade que não se encaixam em seus esquemas conceituais previamente estabelecidos precisa, ela mesma, ser descartada. Em seu lugar, é necessário que ocorra a abertura à interdisciplinaridade.

Essa necessidade é enfatizada no livro "Formas jurídicas e mudança social", que descreve trajetórias do pensamento jurídico com engastes na política e na economia, e que elabora uma crítica a mentalidades jurídicas atreladas a esquemas conceituais desenvolvidos a partir de elucubrações metafísicas, e que fecham a percepção jurídica em si mesma (CASTRO, 2012). Castro associa a formação jurídica tradicional - de caráter conceitualista e formalista - à incapacidade do direito para contribuir de maneira relevante para a estruturação de políticas públicas e da política econômica, para além de papéis meramente instrumentais, em que o(a) jurista é convocado(a) para versar decisões políticas ou econômicas em roupagem jurídica. Ou seja, o direito fechado em si mesmo, ao não dar conta de uma realidade em transformação, falha em prover as bases para a parametrização jurídica das políticas públicas (CASTRO, 2012). E acaba sendo instrumentalizado por outras áreas (ou seja, limita-se a atuar como ferramenta).

Nesse sentido, David Kennedy afirma que "as convenções técnicas profissionais que governam a produção acadêmica no campo jurídico desencorajam pronunciamentos a respeito das grandes tendências na vida econômica e política global". Para o autor, a "tendência jurídico-acadêmica é a análise de foco restrito, refinando e restaurando os léxicos existentes de exercício da autoridade, doutrina e teoria" (2013, p. 9).

Kennedy propõe que o direito pode desempenhar papel de reordenação em grande escala da vida política e econômica. Para isso, seria no entanto necessário "fundir" a análise jurídica com elementos da economia política, de modo a passar a perceber "as dinâmicas de desigualdade; as distribuições do crescimento; as reproduções de hierarquias dentro de e entre setores, regiões, nações e culturas na liderança e re- 
tardatários" (2013, p. 12). Ou seja, o autor propõe um verdadeiro treinamento intelectual e profissional cruzado de juristas com a economia política para favorecer a reforma (juridicamente pautada) de arranjos e padrões regulatórios de interação social e econômica, inclusive no âmbito das relações internacionais (2013, p. 47).

Justifica-se, dessa maneira, que o olhar jurídico deve se abrir e se transformar para capturar, com o auxílio de outros campos, fenômenos normativos que contribuem para a construção social do "normal", ou seja, do que as pessoas entendem como "ordem", como comportamentos e papéis sociais que "devem ser". Como aponta Castro:

...as decisões de política econômica afetam de maneira diferenciada as ações atuais e planejadas de grupos e indivíduos, com reflexos sobre a formação de suas concepções sobre o que são (em termos da fruição presente), ou devam ser, os seus direitos. Isso precisa ser compreendido pela análise jurídica no tratamento de questões relevantes para a configuração institucional da política econômica, tanto no plano doméstico como no da cooperação econômica internacional (2009, p. 24).

A partir da articulação interdisciplinar ${ }^{18}$ de conhecimentos da economia, da ciência política e das relações internacionais (entre muitos outros campos), o(a) jurista pode adquirir condições para propor reformas que orientem políticas públicas, a política econômica e a cooperação internacional para que passem a favorecer a fruição de direitos fundamentais e a habilitação econômica de grupos e indivíduos, de modo conciliado com o crescimento econômico (mais sobre isso será dito adiante). Ou seja, a proposta de trazer ao direito o papel de coordenação de políticas exige do(a) jurista a capacidade de emprego conjugado de saberes de áreas que, embora distintas como disciplinas, representam aspectos comuns das interações sociais e econômicas. O

18 Entende-se a interdisciplinaridade como "o diálogo com diversos campos de elaboração intelectual", de modo a abranger tanto contribuições conceituais quanto metodológicas de diversas disciplinas (CASTRO, 2009, p. 23). 
direito não pode se fechar a representações intelectuais que the são alternativas (CASTRO, 2012, p. 216).

No entanto, é necessário fazer ressalva quanto a perigos no uso da interdisciplinaridade no campo jurídico. Certas representações jurídicas se valem da interdisciplinaridade para substituir critérios de normatividade jurídica por outros, transplantados de outros campos, como fazem a Análise Econômica do Direito (cf. SALAMA, 2008; TIMM, 2012) e o movimento Law \& Finance (cf. LA PORTA et al., 1997; 1998). Para além do uso desejável do intercâmbio entre as "formas" jurídicas e aquelas de outras disciplinas, que permitem a expansão da percepção de fenômenos com significância normativa na sociedade, essas correntes substituem o critério do "bom" e do "desejável" por racionalidades econômicas. O direito passa estar em função da economia, porque o critério de validação da norma jurídica passa a ser sua capacidade de promover a eficiência econômica. O "justo", inclusive o "justo social", é substituído pela relação de "melhor custo-benefício". De forma análoga, a importação de métodos de forte ênfase descritiva da ciência política pode levar o(a) jurista a substituir formulações de "dever ser" por posturas conservadoras de aceitação das instituições postas, assim contribuindo para legitimar hierarquias já existentes.

Ao valer-se da interdisciplinaridade, o(a) jurista precisa ter o cuidado para não assumir posição meramente instrumental em relação a outros campos do saber, que contribuem para a permanência da inabilitação jurídica para balizar a construção do que é desejável em políticas públicas e nas medidas de política econômica.

Por fim, não deve ser considerado juridicamente aceitável que uma economia cresça sem que os ganhos do crescimento sejam equanimemente distribuídos, ou seja, "sem que ao mesmo tempo esteja assegurada a efetiva fruição de direitos fundamentais e direitos humanos pelos membros da sociedade como um todo" (CASTRO, 2011, p. 16). Concebe-se, dessa maneira, que também a noção de "justiça econômica" deve ser pautada por critérios jurídicos (cf. CASTRO, 2009, p. 41,49 ), de modo a orientar as preocupações com o aspecto econômico da competitividade (que inclui considerações sobre crescimento eco- 
nômico, produtividade, lucratividade, eficiência etc.) e com o aspecto da equidade, da distribuição de renda, da fruição equânime dos ganhos econômicos etc., correspondentes a direitos econômicos e sociais. Sob essa perspectiva, "[s]endo plenamente convencionais, são as instituições (políticas públicas, políticas econômicas, mecanismos de cooperação internacional) que devem ser mudadas para se adaptarem ao exercício da fruição de direitos humanos e fundamentais, não o inverso" (CASTRO, 2009, p. 46).

\section{CONSIDERAÇões FINAIS}

A ideia transversal ao presente ensaio foi a de multiplicidade ou pluralidade. A partir dela (já que os fenômenos normativos são também múltiplos ou plurais), constataram-se insuficiências no olhar jurídico que correspondem à sua perda de espaço, e que provocam o pensamento acerca de possibilidades de sua reestruturação.

Inicialmente, após breve caracterização geral do direito como um dos referenciais para ordenação de relações sociais, enfatizou-se que as titularidades, que conformam posições juridicamente protegidas, podem ser moduladas de modo a i) conservar interesses frente a uma realidade em transformação; ii) abrigar e legitimar novos interesses preponderantes, e (iii) remanejar titularidades e promover transformação social. Para além dessas funcionalidades, destacou-se que, em concepção alternativa, o direito pode ser encarado como i) objetivo (dimensão substantiva); ii) ferramenta (dimensão instrumental); iii) arranjo institucional (dimensão estruturante) e ainda como iv) vocalizador de demandas (dimensão legitimadora). Observou-se, nesse percurso, a pluralidade de funções, dimensões ou papéis atribuídos ao direito.

$\mathrm{Na}$ sequência, foram propostos dois grandes recortes para abordar a multiplicidade de acepções da palavra "direito": i) o direito institucionalizado como norma e o ii) direito como representação intelectual de caráter jurídico.

Quanto ao primeiro eixo desse recorte, além de aspectos relacionados às noções de direito objetivo e subjetivo, o ensaio abordou questões 
ligadas às fontes, aplicação e dinâmica do direito. Notou-se que, para além das fontes de caráter formal ou ligadas à atividade estatal, há também fontes plurais, inclusive as de natureza privada, e as que alcançam elementos das relações internacionais. No que diz respeito à aplicação, foram abordados aspectos ligados à sanção, a outros constrangimentos iníquos - com destaque para a ameaça da chamada "fuga de capital" e à obediência espontânea à norma. No que tange à dinâmica, a principal constatação obtida foi a de que nem todas as transformações institucionais podem ser explicadas pelo recurso à tradicional "doutrina das fontes do direito". Enfatizou-se, nesse sentido, a importância de abranger fontes informais de transformação institucional, bem como - mais uma vez - elementos que alcançam as relações internacionais, enfim: expressões de normatividade que incidem para a construção do normal, da ordem social, e que portanto afetam padrões de interação e de ação de pessoas e autoridades.

$\mathrm{Na}$ abordagem do direito como "representação intelectual", o direito foi entendido em sua pluralidade de áreas de saber, campos ou até mesmo correntes de pensamento. Apontou-se, nesse sentido, haver embates que compreendem desde os níveis mais abrangentes - e que envolvem a própria normatividade e os critérios para a validade das normas jurídicas - até o interior das disciplinas jurídicas. Uma importante consideração, para além desse aspecto, diz respeito à perda de espaço das representações jurídicas frente a referenciais concorrentes (sobretudo econômicos) no fornecimento dos materiais intelectuais (argumentos, conceitos, vocabulários) que orientam o exercício da autoridade, refletindo-se nos contornos assumidos pelas políticas públicas e pela política econômica.

$\mathrm{O}$ apontamento mencionado encontra-se fundamentalmente ligado à ausência de monopólio do direito como discurso sobre a normatividade, abordado na última seção do texto. A partir dessa constatação, foi possível apontar para a necessidade de reformulação do direito, de abertura do olhar jurídico, sobretudo (mas não só) para elementos da economia. Sendo múltiplas as ocorrências de normatividade relevantes para a ordenação social, o olhar jurídico precisar ser interdisciplinar, 
sob pena de perder relevância - como já tem ocorrido - enquanto um discurso normativo em meio a tantos outros disponíveis.

De fato, o direito precisa se reinventar para que possa fornecer materiais para pautar o exercício da autoridade, os padrões de interação e ação de pessoas e governos. Nos últimos dois últimos anos (20152016), essa necessidade tem se revelado ainda mais premente no Brasil. O país experimentou sucessivas medidas de políticas públicas e de política econômica que, orientadas pelo objetivo de "conquista da confiança" dos agentes dos mercados - ou seja, a evitar a "fuga de capital" -, têm promovido retrocessos em termos da fruição de direitos fundamentais. O presente ensaio buscou, nesse sentido, retirar da abordagem das múltiplas acepções do "direito", a proposta de que o olhar jurídico precise se equipar para desempenhar o papel de adaptar políticas públicas e medidas de política econômica a objetivos concebidos em termos de objetivos jurídicos, ao contrário do que tem sido a prática prevalente, de subserviência instrumental frente a referenciais econômicos.

\section{REFERÊNCIAS}

BERMAN, P. S. From international law to law and globalization. Columbia Journal of Transnational Law, 43 (1), 2005, p. 485-556.

BERMAN, P. S. Global legal pluralism. Southern California Law Review, 80 (1), 2007, p. 1.155-1.238.

BHAGWATI, J. In defense of globalization. New York: Oxford University Press, 2004.

BLYTH, M. The transformation of the Swedish model: economic ideas, distributional conflict, and institutional change. World Politics, 54 (1), 2001, p. $1-26$.

CASTRO, M. F. Análise Jurídica da Política Econômica. Revista da Procuradoria-Geral do Banco Central, 3 (1), 2009, p. 7-71.

CASTRO, M. F. Direito, tributação e economia no Brasil: aportes da Análise Jurídica da Política Econômica. Revista da Procuradoria-Geral da Fazenda Nacional, 1 (2), 2011, p. 23-51. 
CASTRO, M. F. Formas jurídicas e mudança social: interações entre o direito, a filosofia, a política e a economia. São Paulo: Saraiva, 2012.

CASTRO, M. F. Instituições econômicas: evolução de seus elementos constitucionais na sociedade de mercado. Revista de Direito Empresarial, 6 (2), 2006, p. 41-62.

CASTRO, M. F. Jurisdição, Economia e Mudança Social. In: KOERNER, A.; DUARTE, F. (orgs.). Justiça Constitucional no Brasil: Política e Direito. Rio de Janeiro, Revista do TRF da Segunda Região, 2010, p. 143-74.

CASTRO, M. F. Política e relações internacionais: fundamentos clássicos. Brasília: Editora UnB, 2005.

COUTINHO, D. R. Direito, desigualdade e desenvolvimento. São Paulo: Saraiva, 2013.

HALL, R. B.; BIERSTEKER, T. J. The emergence of private authority in the international system. In: HALL, R. B.; BIERSTEKER, T. J. (Org.). The emergence of private authority in global governance. Cambridge: Cambridge University Press, 2004, p. 3-22.

HAY, C. Constructive institutionalism. In: RHODES, R. A. W.; BINDER, S. A.; ROCKMAN, B. A. The Oxford handbook of political institutions. Oxford: Oxford University Press, 2006, p. 56-74.

HELLEINER, E. States and the reemergence of global finance: from Bretton Woods to the 1990s. Ithaca: Cornell University Press, 1994.

KELSEN, H. Teoria pura do direito: introdução à problemática científica do direito, 7. ed. São Paulo: Revista dos Tribunais, 2011.

KENNEDY, D. Law and the political economy of the world. Leiden Journal of International Law, 26 (1), 2013, p. 7-48.

KENNEDY, D. Some caution about property rights as a recipe for economic development. Accounting, Economics and Law, 1 (1), 2011, p. 11-62.

LAKE, D. A. Rightful rules: authority, order, and the foundations of global governance. International Studies Quarterly, 54 (1), 2010, p. 587-613.

LA PORTA, R.; LOPEZ-DE-SILANES, F.; SHLEIFER, A.; VISHNY, R. W. 1997. Legal determinants of external finance. The Journal of Finance, 52 (3), 2010, p. 1.131-1.150. 
LA PORTA, R.; LOPEZ-DE-SILANES, F.; SHLEIFER, A.; VISHNY, R. W. Law and finance. The Journal of Political Economy, 106 (6), 1998, p. 1.1131.155 .

MANSELL, W.; METEYARD, B.; THOMSON, A. A critical introduction to law, 3. ed. London: Cavendish Publishing, 2004.

NASSER, S. H. Fontes e normas do direito internacional: um estudo sobre a soft law, 2. ed. São Paulo: Atlas, 2006.

PENA, H. Direito subjetivo na era dos códigos e das constituições: o problema da indefinição de conteúdo, em perspectiva histórica. Quaestio iuris, 7 (2), 2014, p. 840-864.

SALAMA, B. M. O que é pesquisa em direito e economia? Cadernos Direito GV, 5 (2), 2008, p. 1-58.

SHAFFER, G. Transnational legal ordering and state change. In: SHAFFER, G. (Org.) Transnational legal ordering and state change. Cambridge: Cambridge University Press, 2013, p. 1-22.

TIMM, L. B. (Org.). Direito e economia no Brasil. São Paulo: Atlas, 2012.

WEIL, P. Towards relative normativity in international law? American Journal of International Law, 77 (3), 1983, p. 413-442.

WOLKMER, A. C. Pluralismo jurídico: fundamentos de uma nova cultura do direito, 3. ed. São Paulo: Alfa Omega, 2001.

\section{SOBRE O AUTOR}

\section{Hugo Luís Pena Ferreira}

Doutor em Direito (UnB). Mestre em Direito (UFSC). Professor do Curso de Direito da UFG, Regional Jataí.

CV: http://lattes.cnpq.br/2438328359443143

E-mail: hugopena@gmail.com

Submetido em:2-3-2018

Aceito em: 17-5-2018 